\title{
Polyolefin oxo-degradation accelerators - a new trend to promote environmental protection
}

\author{
Barbara Cichy ${ }^{1 *}$, Jacek Kwiecień ${ }^{1}$, Magdalena Piątkowska ${ }^{1}$, Ewa Kużdżał ${ }^{1}$, Edyta Gibas ${ }^{2}$, \\ Grażyna Rymarz ${ }^{2}$ \\ ${ }^{1}$ Fertilizers Research Institute, Department of Inorganic Chemistry "IChN" in Gliwice, ul. Sowińskiego 11, 44-101 Gliwice, \\ Poland \\ ${ }^{2}$ Institute for Engineering of Polymer Materials \& Dyes in Toruń, Department of Paints \& Plastics in Gliwice, Chorzowska \\ 50A, 44-100 Gliwice, Poland \\ * Corresponding author: e-mail: bcichy@ichn.gliwice.pl
}

\begin{abstract}
The paper presents the results of the tests on the preparation of iron (III) stearate - the most prominent oxo-biodegradation agent for polyolefinic plastics. The process chosen for testing was the double precipitation process, using stearic acid alkalised with soda lye and iron (III) chloride or iron (III) sulphate. A number of iron (III) stearate preparation methods described in the literature were tested and an analytical procedure for monitoring the process was developed using both the classical and instrumental techniques. FTIR spectroscopy is the most useful technique for the product quality control and identification. During the study the characteristics of the proper product were also determined using the DSC methods. Microscopy and laser diffraction particle size analysis were applied to determine the size of the precipitated product grains. An application sample of the product obtained by the double decomposition method from iron (III) sulphate as the iron carrier has successfully passed the application tests in the polyethylene packaging film.
\end{abstract}

Keywords: degradable plastics, oxo-biodegradation, oxo-biodegradable polyolefins, prodegradants, metal carboxylates, iron (III) stearate.

\section{INTRODUCTION}

Progress in polymer science has resulted in the launch of the mass production of synthetic polymeric materials. In 2006 the production volume reached 245 million tonnes. In recent years (at the break of the 21st century) the production of synthetic polymers was growing at an annual rate of 5 to $5.5 \%$. This growth may be attributed mainly to the global dissemination of basic polyolefin polyethylene (PE), polypropylene (PP)), polyvinyl chloride (PVC) and, more recently, polyethylene terephthalate (PET) manufacturing processes. Environmental image is becoming an important factor in determining the market position of a polymeric material. That image depends on the processes and raw materials used for the manufacturing of these materials and, more importantly, on product recyclability or biodegradability and on the use of renewable resources ${ }^{1}$.

A large fraction of commodity plastics is used for the manufacture of packaging materials. The Member States of the European Union generate ca. 1.3 billion tonnes of waste each year. Of this 14 percent is municipal waste, and a large part of that is waste packaging. The current global production volume of plastics is 20 times higher than it was 50 years ago, $90 \%$ of all products turn into waste within six months from the date of their purchase. More than $80 \%$ of consumer plastic waste goes to landfills, $8 \%$ is incinerated, and only $7 \%$ is reprocessed. According to estimates, the annual volumes of packaging waste generated in Poland are as follows: ca. 530 thousand tonnes of paper and cardboard packaging, 466 thousand tonnes of glass packaging, 276 thousand tonnes of plastic and laminate packaging and 130 thousand tonnes of metal packaging. The amount of spent packaging per capita in Poland is ca. $70 \mathrm{~kg}$ and is still much lower than in Western Europe. The world figure is ca. $150 \mathrm{~kg}$. Nonetheless the problem of waste plastic packaging is becoming more and more eminent ${ }^{2}$.

The more developed the country's economy is and the more affluent its citizens are, the larger and wealthier is its packaging market, expressed in terms of the amount of packaging used, both in commodity turnover and in households. The world market value is estimated at 408 billion Euros, which corresponds to a per capita value of ca. 61 Euros. In the most economically developed and most highly civilised countries this figure ranges from 260 to 350 Euros. The share of plastics in the packaging markets of Poland, Europe and the world is $36.7 \%, 38 \%$ and $31.7 \%$, respectively ${ }^{3}$.

Today plastics replace many traditional materials, and their versatility arises from their specific properties: plastics are lightweight, water permeable, chemically stable, non-toxic and resistant to biodegradation. However, the features, which made plastics an inherent attribute of everyday life, are also the cause of difficulties in the disposal thereof. Polyolefins (mainly polyethylene (PE) and polypropylene (PP)) due to their high processability, low price, functionality, biological inertness and aesthetic values are among the most widespread commodity plastics.

The European Parliament and Council Directive 94/62/ $\mathrm{EC}$ and its subsequent revisions (2004/12/EC [OJ L047, 18/02/2004]; 2005/20/EC [OJ L070, 16/03/2005]), as well as Polish regulations adopted after the Act on Waste came into force in 2001 (Dz. U. No. 94, item 628, as amended), obligate the Member States of the European Union to implement measures to support the development of "clean" technologies. Those regulations also require the Member to recover substances and materials from waste by recycling, reuse, regeneration or other processes of secondary materials utilisation and to prevent or reduce waste generation and environmental impact thereof during manu- 
facture, use and at the end of the life cycle. One of the solutions aimed at mitigating the problem of the growing amount of waste is the development of biodegradable plastics used mainly for the manufacture of disposable packaging which, after use, should decompose rapidly under natural conditions without posing a hazard to the environment ${ }^{4,5}$.

Degradable polymers are sensitive to various physical, chemical or biological factors which induce their gradual decomposition. Some of the degradable materials can be obtained from renewable sources, in contrast to petroleum-derived polymers (such as polyethylene or polypropylene $)^{\mathbf{1}}$. One group of degradable polymers are biopolymers, including natural biopolymers (cellulose, starch, pectin, proteins) and synthetic biopolymers obtained from biomonomers (e.g. bioethanol). Synthetic polymers obtained from traditional petroleum derivatives and containing degradation-inducing additives may also be counted as materials of this group. Biocomposites, usually comprising a synthetic polymer and an organic filler of natural origin (wood flour, modified starch, natural fibres), are growing in significance ${ }^{1,7}$. Among biopolymers based on natural raw materials of highest practical importance are those based on polylactides, those based on starch and composites containing wood flour ${ }^{8}$. The cost of manufacturing of the synthetic commodity polymers, including polyolefins, still remains much lower than that of manufacturing a biopolymer or a biocomposite. Therefore, plastic packaging waste reduction methods involving the use of additives that sensitise the plastics to degrading factors, such as UV radiation, oxygen, moisture, bacteria, etc., are gaining in importance. These methods make use of complexes and salts of variable valence metals, e.g.: $\mathrm{Fe}, \mathrm{Mn}$ or $\mathrm{Co}$, which enhance the degradability of synthetic polymers under the action of sunlight and oxygen, as well as under composting conditions, by catalysing the oxidative degradation of the polymer chain, followed by biodegradation under the action of natural biological factors $\mathbf{6}, \mathbf{1 0}$.

One may distinguish the following techniques of biodegradation induced by a catalysing agent:

- photodegradation - where the material reacts to ultraviolet light; as it is not oxo-biodegradable, it will not break down in a landfill or in a dark environment;

- hydro-biodegradation - where in most cases the material is based on starch, degradation requires moisture and biologically active environment. Derived mostly from corn or other crops, therefore may also contain large amounts of polyesters. Some of these products are obtained from genetically modified crops;

- oxo-biodegradation - where materials degrade in every type of the environment, either open or confined, even in the absence of water. These materials may be programmed by the manufacturer to degrade after a defined time in order to meet the user's requirements. They are stronger and more versatile than the previous alternatives, and this technology is the least expensive. The plastics can be recovered and remanufactured from the recovered material. Carbon is released at a slower rate during the decomposition of an oxo-biodegradable plastic, making it available to growing plants. These plastics may be used in direct contact with the food and they are safe for the soil ${ }^{3,4,7}$.
Oxo-degradation is defined by TC249/WG9 of CEN (the European Committee for Standardization) as "degradation identified as resulting from oxidative cleavage of macromolecules", and oxo-biodegradation as "degradation identified as resulting from the oxidative and cell-mediated phenomena, either simultaneously or successively". That, in fact, is exactly what happens to oxo-biodegradable plastics. In June 2009 the German Institute for Energy and Environmental Research concluded that petroleumbased plastics have a much better life cycle assessment than compostable plastics, particularly when subjected to recycling. Oxo-biodegradable plastics undergo self-destruction within a few years only. Oxo-biodegradation itself consists in the decomposition of the plastic into water, carbon dioxide and trace amounts of biomass. More than 5 billion products made of oxo-biodegradable plastics were marketed globally during the last year ${ }^{2}$.

The most-used prodegradants of the TDPA type (Totally Degradable Plastic Additives) are the carboxylates of transition metals: $\mathrm{Fe}, \mathrm{Mn}$, Co. The mechanism of action of TDPA, described in $^{\mathbf{1 4}}$, is as follows:

$$
\begin{aligned}
& M\left(\mathrm{OOR}^{\prime}\right)_{3} \longrightarrow \mathrm{hv} \longrightarrow \mathrm{M}\left(\mathrm{COOR}^{\prime}\right)_{2}+\mathrm{R}^{\prime} \mathrm{COO}^{\bullet} \\
& \mathrm{R}^{\prime} \mathrm{COO} \stackrel{h v}{\longrightarrow} \mathrm{R}^{\bullet}+\mathrm{CO}_{2} \\
& R^{\bullet}+\mathrm{RH} \longrightarrow \mathrm{R}^{\bullet}+\mathrm{R}^{\prime} \mathrm{H} \\
& \mathrm{R}^{\bullet}+\mathrm{O}_{2} \longrightarrow \mathrm{ROO}^{\bullet} \\
& \mathrm{ROO}^{\bullet}+\mathrm{RH} \longrightarrow \mathrm{ROOH}+\mathrm{R}^{\bullet} \\
& \left(\mathrm{RH}=\text { Polyethylene } \mathrm{R}^{\prime}=\text { alkyl group }\right) \\
& \mathrm{ROOH}+M^{n+} \longrightarrow \mathrm{RO}+M^{(n+1)+}+\mathrm{OH}^{-} \\
& \mathrm{ROOH}+M^{(n+1)+} \longrightarrow \mathrm{ROO}^{\bullet}+M^{n+}+H^{+} \\
& 2 \mathrm{ROOH} \stackrel{M^{n+} / M^{(n+1)+}}{\longrightarrow} \mathrm{RO}^{\bullet}+\mathrm{ROO}^{\bullet}
\end{aligned}
$$

One of the transition metal carboxylates is iron (III) stearate, which is relatively frequently mentioned in scientific literature and patent specifications as an effective oxo-biodegradant ${ }^{12,15,17,18}$.

Iron(III) stearate can be obtained by the following methods [18]:

- direct reaction between acid and oxide at an elevated temperature $\left(150-200^{\circ} \mathrm{C}\right)$,

- metathesis reaction: a water-soluble stearate salt (sodium or calcium stearate) reacts with a soluble salt of $\mathrm{Fe}(\mathrm{III})$, and the formed iron(III) carboxylate, being scarcely soluble in water, precipitates from the system. The disadvantage of this process is its low efficiency and the presence of contaminants in the reaction product,

- in the first step the fatty acid is saponified with soda lye at a temperature above the melting point of the acid $\left(\right.$ ca. $90^{\circ} \mathrm{C}$ ), and the product of saponification reacts at a lower temperature $\left(\mathrm{ca} .60^{\circ} \mathrm{C}\right)$ with a soluble salt of iron (chloride or sulphate).

Excess of stearic acid or its salt, used in the metathesis reaction, is then removed from the final product by washing with tetrahydrofuran providing, in effect, a very pure product. The process is complex and expensive ${ }^{\mathbf{1 0}, 12,18}$. The ultimate method-the double decomposition reactionis the most used method of preparing carboxylates applicable in biodegradable PE films, whereas the problem here is the incomplete reaction of the stearic acid. Of disadvantage is also $7-10 \%$ sodium stearate soap residue 
in the final product. It makes the product filtration difficult, and in the final application (packaging films) it induces migration from the plastic and impairs the processability of the plastic ${ }^{10}$. This problem can be obviated by breaking up the process into several stages, wherein the solid product is filtered, concomitant salt $(\mathrm{NaCl}$ or $\mathrm{Na}_{2} \mathrm{SO}_{4}$ ) is removed from the reaction medium, and then the filtered product is alkalised again with soda lye taken in proportional amount to the amount of the unreacted stearic acid, and the soap now formed (sodium stearate) is separated by precipitation of a metal stearate, e.g. iron stearate. There are several such stages, depending on the required purity of the product. In most cases there were 4 repetitions of the cycle: saponification - precipitation, with smaller amounts of reagents being used in each subsequent stage. This way the removal of unreacted stearic acid from the product was nearly complete.

The aim of the work outlined in this paper was to determine the parameters of the synthesis of transition metal carboxylates, including iron(III) stearate, of appropriate quality for application as an oxo-biodegradant for polyethylene packaging film. The tests carried out are one of the elements of developing a process for the preparation of complex $\mathrm{Fe}$ and Mn carboxylates, which make up the core of a concentrate for thermo- and oxo-biodegradable polyethylene films. This paper discusses the techniques of preparing compounds of this type and describes the methods developed for carrying out qualitative and quantitative control of the product using FTIR and DSC techniques.

\section{EXPERIMENTAL}

\section{Methods of iron (III) stearate synthesis:}

Iron (III) stearate synthesis trials were conducted using the following methods:

1. Metathesis reaction: dissolved iron (III) chloride was added to the aqueous solution of calcium stearate. The mixture was agitated at $65^{\circ} \mathrm{C}$ for 30 to 40 minutes. The product precipitate was separated from the liquor on a Büchner funnel ${ }^{15}$. The product was dried at $60^{\circ} \mathrm{C}$. The reaction proceeded according to the following equation: $3\left(\mathrm{C}_{17} \mathrm{H}_{35} \mathrm{COO}\right)_{2} \mathrm{Ca}+2 \mathrm{FeCl}_{3} \longrightarrow 2\left(\mathrm{C}_{17} \mathrm{H}_{35} \mathrm{COO}\right)_{3} \mathrm{Fe}+3 \mathrm{CaCl}$

2. Metathesis reaction: solution of iron(III) chloride was added to sodium stearate dissolved in water. The suspension was agitated at $80-90^{\circ} \mathrm{C}$ for 30 to 40 minutes. The precipitate was filtered on a Büchner funnel, and then dried at $60^{\circ} \mathrm{C}^{19}$. The reaction proceeded according to the following equation:

$3\left(\mathrm{C}_{17} \mathrm{H}_{35} \mathrm{COO}\right) \mathrm{Na}+\mathrm{FeCl}_{3} \longrightarrow\left(\mathrm{C}_{17} \mathrm{H}_{35} \mathrm{COO}\right)_{3} \mathrm{Fe}+3 \mathrm{NaCl}$

3. Metathesis reaction: from sodium stearate and iron(III) salt, wherein stearic acid was saponified with soda lye immediately before conducting the metathesis reaction; as the acid was not completely saponified during one reaction cycle, the saponification of the remaining unreacted acid was repeated using soda lye in an amount proportional to the amount of unsaponified acid, and the product of this reaction was converted again into iron(III) stearate. The acid-base processes may be repeated many times over, whereas satisfactory results were achieved after 3 to 4 cycles, attaining a stoichiometric excess of iron(III) chloride of about $50 \%$. The reaction temperature was maintained at $65-90^{\circ} \mathrm{C}$ under continuous agitation. The precipitate was filtered on a Büchner funnel, and then dried at $60^{\circ} \mathrm{C}^{20}$. The course of the reaction can be described with the following equations:

$\left(\mathrm{C}_{17} \mathrm{H}_{35} \mathrm{COO}\right) \mathrm{H}+\mathrm{NaOH} \longrightarrow\left(\mathrm{C}_{17} \mathrm{H}_{35} \mathrm{COO}\right) \mathrm{Na}+\mathrm{H}_{2} \mathrm{O}$
$3\left(\mathrm{C}_{17} \mathrm{H}_{35} \mathrm{COO}\right) \mathrm{Na}+\mathrm{FeCl}_{3} \longrightarrow\left(\mathrm{C}_{17} \mathrm{H}_{35} \mathrm{COO}\right)_{3} \mathrm{Fe}+3 \mathrm{NaCl}$

or

$6\left(\mathrm{C}_{17} \mathrm{H}_{35} \mathrm{COO}\right) \mathrm{Na}+\mathrm{Fe}_{2}\left(\mathrm{SO}_{4}\right)_{3} \longrightarrow 2\left(\mathrm{C}_{17} \mathrm{H}_{35} \mathrm{COO}\right)_{3} \mathrm{Fe}+3 \mathrm{Na}_{2}\left(\mathrm{SO}_{4}\right)$

\section{Methods of quality control}

Quality control of the products obtained was based on instrumental methods: FTIR spectroscopy and differential scanning calorimetry (DSC). The DSC technique was applied to analyse iron stearate (the product) and stearic acid. The temperature range applied was 25 to 200 $(300)^{\circ} \mathrm{C}$, sample heating rate $2^{\circ} \mathrm{C} / \mathrm{min}$, argon atmosphere. Heats of transitions and temperatures corresponding to peak maxima were determined. A Mettler Toledo DSC $822 \mathrm{e}$ instrument was used in the tests.

FTIR spectrograms of the tested samples were recorded within the infrared range of $4000-400 \mathrm{~cm}^{-1}$ using the transmission technique, potassium bromide pelletizing and attenuated total reflection (ATR) technique. The potassium bromide pelletizing technique consisted in blending dry and powdered $\mathrm{KBr}$ with the sample at a defined ratio, followed by compressing under vacuum in a press and transforming into a transparent pellet. In the ATR method a prism made of highly refractive material (diamond crystal) was used, the sample being positioned and pressed onto the crystal. Infrared radiation is beamed from the source through one of the walls of the prism and leaves the prism after being completely reflected at the opposite wall. The total internal reflection occurs when the angle of incidence of the beam at the opposite wall is greater than the critical angle. The reflective spectra obtained were similar, though not identical, to transmission spectra, which is the consequence of the fact that band intensity in the reflective spectrum increases with wavelength. As functional and other groups of atoms, irrespective of the structure of the remainder of the molecule, absorb infrared radiation in a relatively narrow range of frequencies, comparison (correlation) of the spectra of two substances is a good check of their identity. The FTIR spectrophotometer used was Nicolet 380 from Thermo Fisher Scientific. The obtained transmission and ATR spectra were compared with the literature data (Table 1) and with a commercial product from TCI Europe, which in view of the lack of a commercially available standard, was treated as a reference product.

An attempt was also made to apply the FTIR technique to quantitatively determine the prodegradants prepared on a laboratory scale. Due to the limited solubility of metal stearates in most of the solvents available and appropriate for FTIR analysis, the quantitative analysis of samples of prodegradants in solutions proved impracticable. The two other techniques were not taken into consid- 
Table 1. Literature FTIR data of stearic acid and some stearates

\begin{tabular}{|c|c|c|c|c|c|c|c|}
\hline $\begin{array}{c}\text { HSt, } \\
{[18,19]}\end{array}$ & $\begin{array}{l}\text { LiSt, } \\
{[19]}\end{array}$ & $\begin{array}{l}\text { NaSt, } \\
{[18,19]}\end{array}$ & $\begin{array}{c}\mathbf{C o S t}_{2}, \\
{[18]} \\
\end{array}$ & $\begin{array}{c}\mathbf{Z n S t}_{\mathbf{2}} \\
{[17,16]} \\
\end{array}$ & $\begin{array}{c}\mathbf{P b S t}_{2}, \\
{[17]}\end{array}$ & $\begin{array}{r}\mathbf{F e S t}_{3} \\
{[20,21]} \\
\end{array}$ & \multirow{2}{*}{$\begin{array}{l}\text { Type of characteristic bands for } \\
\text { unit data }\end{array}$} \\
\hline \multicolumn{7}{|c|}{ Range of characteristics bands for unit data, $\mathrm{cm}^{-1}$} & \\
\hline$-3472(b)$ & $3446(b)$ & - & - & - & - & $-(3415)$ & $\begin{array}{l}\text { Broad absorption of stretching vibr. O-H, } \\
\text { of hydrated water }\end{array}$ \\
\hline $\begin{array}{l}2960, \\
2920,2922 \\
2850,2853\end{array}$ & $\begin{array}{l}2960(\mathrm{~ms}) \\
2914(\mathrm{vs}) \\
2848(\mathrm{vs})\end{array}$ & $\begin{array}{l}2960 \\
2920 \\
2850\end{array}$ & $\begin{array}{l}2970 \\
2920 \\
2850\end{array}$ & $\begin{array}{l}2918,- \\
2843,-\end{array}$ & $\begin{array}{l}2919 \\
2850\end{array}$ & $\begin{array}{r}-(2956) \\
\sim 2925(2918) \\
\sim 2850(2850) \\
\end{array}$ & $\begin{array}{l}\text { Antisymmetric stretching } \mathrm{CH}_{3}, \mathrm{C} \\
\text { Antisymmetric stretching } \mathrm{CH}_{2}, \mathrm{C} \\
\text { Symmetric stretching } \mathrm{CH}_{2}, \mathrm{C}\end{array}$ \\
\hline 2650 & - & - & - & - & - & - & Stretching O-H \\
\hline 1700,1745 & - & - & - & - & - & - & Stretching $\mathrm{C}=\mathrm{O}$ \\
\hline- & $\begin{array}{l}1580(\mathrm{vs}) \\
1556(\mathrm{~s})\end{array}$ & 1560,1561 & $\begin{array}{c}- \\
1532 \\
\end{array}$ & $\begin{array}{c}-1560 \\
1543,1540\end{array}$ & 1513 & $\begin{array}{r}1580(1588) \\
-\quad(1532) \\
\end{array}$ & $\begin{array}{l}\text { Carboxylate antisymmetric stretching } \\
\mathrm{COO}^{-}, \mathrm{C}-\mathrm{O}\left(\omega_{2}\right)\end{array}$ \\
\hline 1468 & $1448(s)$ & $\begin{array}{ll}1475, & - \\
1445, & -\end{array}$ & 1468 & 1467,1472 & 1466 & $\begin{array}{r}1466(1467) \\
(1455)\end{array}$ & Deformation $\mathrm{CH}_{2}$, C-H scissor vibrations \\
\hline 1412,1464 & $1403(s)$ & 1424,1426 & 1400 & 1399,1398 & 1417 & $\sim 1440-$ & $\begin{array}{l}\text { Carboxylate symmetric stretching } \\
\text { COO }^{-}, \mathrm{C}-\mathrm{O}\left(\omega_{1}\right)\end{array}$ \\
\hline 1377 & $\begin{array}{l}1375(\mathrm{~ms}) \\
1350(\mathrm{~s})\end{array}$ & & & & & $\sim 1300(1319)$ & $\begin{array}{l}\text { Symmetric deformation } \mathrm{CH}_{3} \\
\text { Deformation } \mathrm{CH}_{2} \text { band adjacent to } \mathrm{COO}^{-}\end{array}$ \\
\hline 1328 & & some & & & & $-(1311)$ & Twist.and wag. $\mathrm{CH}_{2}$ (progressive bands) \\
\hline $1190-1300$ & $\begin{array}{l}1261(\mathrm{w}) \\
1240(\mathrm{w}) \\
1223(\mathrm{w}) \\
1203(\mathrm{w}) \\
1186(\mathrm{w})\end{array}$ & & & & & & $\begin{array}{l}\text { Rocking } \mathrm{CH}_{3} \\
\text { Deformation COOR }\end{array}$ \\
\hline 940 & $950(w)$ & - & - & - & - & - & $\begin{array}{l}\text { Deformation } \mathrm{COO}^{-}\left(\omega_{3}\right) \text {, deformation } \\
\mathrm{OH}\end{array}$ \\
\hline $720-730,722$ & $719(\mathrm{~s})$ & $720, \quad-$ & 720 & 728 & 725 & $(721)$ & Rocking $\left(\mathrm{CH}_{2}\right)_{\mathrm{n}}, \mathrm{n}>7$ \\
\hline- & - & $538, \quad-$ & - & - & - & $(491)$ & $\mathrm{Me}-\mathrm{O}$ bond \\
\hline
\end{tabular}

Abbreviations : HSt - stearic acid, LiSt- lithium stearate, NaSt - sodium stearate, $\mathrm{CoSt}_{2}-\mathrm{cobalt}_{\text {stearate, }}$

$\mathrm{ZnSt}_{2}$ - zinc stearate, $\mathrm{PbSt}_{2}$ - lead stearate,, $\mathrm{FeSt}_{3}$ - iron(III) stearate; b - broad, s - strong, $\mathrm{m}$ - medium ,

w- weak, vw - very weak.

eration: the $\mathrm{KBr}$ pellets technique because of the nonuniform sample distribution in the pellet, and the ATR technique because of the imperfect contact between the sample and the crystal surface. The content of biodegration inducing additives was determined by the transmission technique directly in the packaging materials (films). A batch of standards, consisting of polyolefin concentrates and catalysts added in various amounts $(0.1 ; 0.2 ; 0.5 ; 1$; $5 ; 10$ and $20 \%$ ferric(III) stearate), prepared at the Institute for Engineering of Polymer Materials and Dyes in Gliwice, was used to produce films containing photooxobiodegradation accelerating additive for the tests. A TQ Analyst EZ Edition (Nicolet 380) software package was used for analytical data processing.

Microscopy and laser diffraction particle size analysis were applied to determine the size of the product grains obtained by precipitation. The shape and size of the product grains introduced into the plastic is an important feature, as even a small quantity of a substance having the nature of a filler has an effect on the rheological processing properties of that plastic. Microscopic examination enabled the assessment of the effect of contaminants on the appearance (e.g. colour) of filler grains.

Application tests of the product obtained were carried out at the Institute for Engineering of Polymer Materials and Dyes (Department of Paints and Plastics in Gliwice). Packaging films were made from LDPE (LyonellBasell) with an admixture of the prodegradant obtained (iron(III) stearate $-\mathrm{FeSt}_{3}$ ) taken in an amount of 0.5 wt. \% $\left(\mathrm{PE}+0.5 \% \quad \mathrm{FeSt}_{3}\right)$ and 1 wt. \% $\left(\mathrm{PE}+1 \% \quad \mathrm{FeSt}_{3}\right)$ and compounded with wood flour (PE/MD30/ $\mathrm{FeSt}_{3}$ contains
$0.5 \% \mathrm{FeSt}_{3}$ and $30 \%$ wood flour). The film was extruded on a Brabender Plasti-Corder PLV 151 machine (extrusion with no blowing applied).

Oxo- and photo-degradation processes during ageing under atmospheric conditions were monitored (in accordance with ASTM D6954-04: Standard Guide for Exposing and Testing Plastics that Degrade in the Environment by a Combination of Oxidation and Biodegradation) by measuring the changes in mechanical properties (strength) (in accordance with PN-EN ISO 527-1 standard: Plastics Determination of tensile properties - Part 1: General principles).

\section{RESULTS AND DISCUSSION}

Among the tested methods of iron(III) stearate preparation by metathesis reaction (Method No1 and No 2) or by double decomposition (Method No 3), the best effects, in terms of the process efficiency and similarity of the product obtained to commercial iron(III) stearate, were achieved in the third method illustrated in the diagram (Figure 1).

Quality control of the products obtained was based on the instrumental methods: FTIR spectroscopy and differential scanning calorimetry (DSC).

The obtained FTIR spectra featured well-resolved bands of high diagnostic value (Table 2).

The commercial product from TCI, which was adopted in the study as the reference product, was not a high-purity product. It contained anionic contaminants, both chlorides and sulphates. The products obtained in the study showed lower conformability with the reference when 
Table 2. Assessment of quality of selected iron(III) stearates prepared on a laboratory scale - FTIR spectrophotometric testing, comparison of characterisitic frequencies

\begin{tabular}{|c|c|c|c|}
\hline \multicolumn{3}{|c|}{ Production batch of $\left(\mathrm{FeSt}_{3}\right)$} & \multirow{3}{*}{ Type of characteristic bands for unit data } \\
\hline $\begin{array}{l}\text { Commercial product } \\
\text { (TCI Europe, Belgia) }\end{array}$ & $\begin{array}{l}\text { Production batch } \\
\text { of (FeSt }{ }_{3} \text { ) from } \\
\text { iron(III) chloride } \\
\text { (Method No 3) } \\
\end{array}$ & $\begin{array}{c}\text { Production batch of } \\
\text { (FeSt }{ }_{3} \text { ) from } \\
\text { iron( III) sulphate } \\
\text { (Method No 3) }\end{array}$ & \\
\hline \multicolumn{3}{|c|}{ Range of characteristics bands for unit data, $\mathrm{cm}^{-1}$} & \\
\hline 3440 & 3442 & 3450 & Stretching vibration $\mathrm{O}-\mathrm{H}$ of hydrated water \\
\hline 2956 & 2955 & 2956 & Antisymmetric stretching $\mathrm{CH}_{3}, \mathrm{C}-\mathrm{H}$ \\
\hline 2918 & 2918 & 2918 & Antisymmetric stretching $\mathrm{CH}_{2}, \mathrm{C}-\mathrm{H}$ \\
\hline 2850 & 2850 & 2850 & Symmetric stretching $\mathrm{CH}_{2}, \mathrm{C}-\mathrm{H}$ \\
\hline 1711 & 1714 & - & Stretching $\mathrm{C}=\mathrm{O}$ \\
\hline 1577 & 1571 & 1577 & $\begin{array}{l}\text { Carboxylate antisymmetric stretching } \mathrm{COO}^{-}, \\
\mathrm{C}-\mathrm{O}\left(\omega_{2}\right)\end{array}$ \\
\hline 1467 & 1467 & 1467 & Deformation $\mathrm{CH}_{2}, \mathrm{C}-\mathrm{H}$ scissor vibrations \\
\hline- & - & - & Carboxylate symmetric stretching $\mathrm{COO}^{-}, \mathrm{C}-\mathrm{O}\left(\omega_{1}\right)$ \\
\hline- & - & - & Symmetric deformation $\mathrm{CH}_{3}$ \\
\hline 1318 & 1315 & 1318 & Deformation $\mathrm{CH}_{2}$ band adjacent to $\mathrm{COOH}$ \\
\hline 1112 & 1112 & 1116 & Deformation COOR \\
\hline- & - & - & Deformation $\mathrm{COO}^{-}\left(\omega_{3}\right)$, deformation $\mathrm{OH}$ \\
\hline 723 & 720 & 723 & Rocking $\left(\mathrm{CH}_{2}\right)_{\mathrm{n}}, \mathrm{n}>7$ \\
\hline 583 & 580 & 583 & $\mathrm{Me}-\mathrm{O}$ bond \\
\hline
\end{tabular}

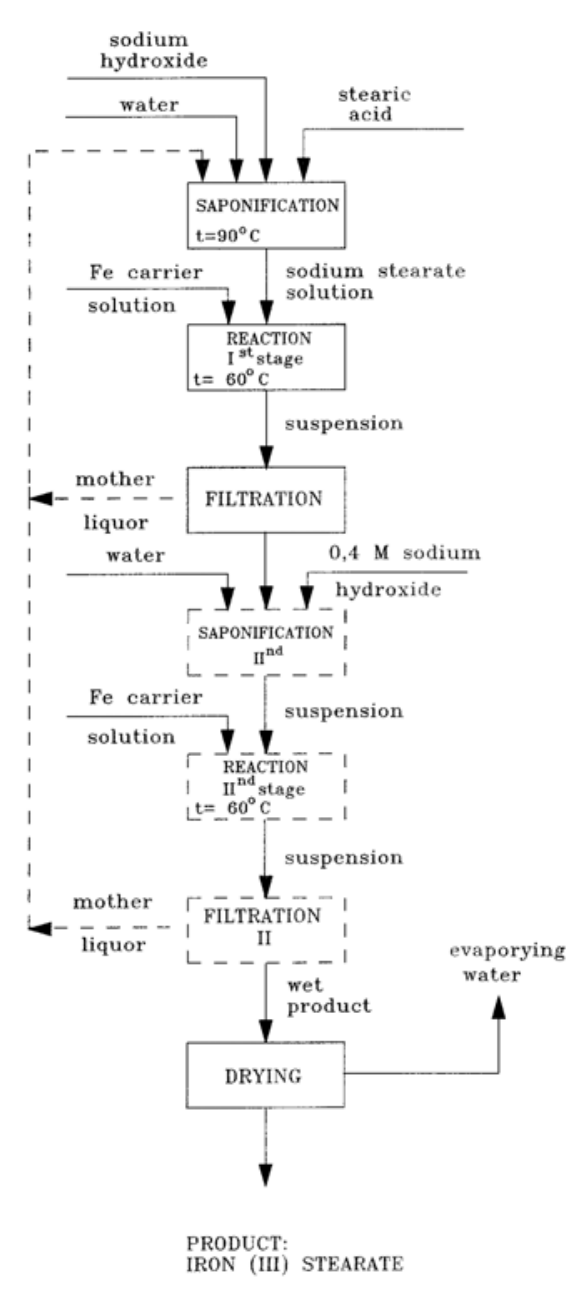

Figure 1. Schematic diagram of iron (III) stearate synthesis

FTIR spectra were compared. The reason may be the lower content of anionic contaminants in the samples obtained (Table 3 ). The synthesis tests provided the products with an over-stoichiometric total iron content, which was not tantamount to stearic acid reacting completely to
iron(III) stearate - the process was monitored by recording FTIR spectra after subsequent stages (I - IV) of the synthesis process (Table 3 ).

Observation of the progress of the stearate synthesis reaction by FTIR spectroscopy (Figure 2) clearly shows that with the course of the process the absorption intensity of the carbonyl group band ( $C=O$ stretching vibrations, ca. $\left.1700 \mathrm{~cm}^{-1}\right)$ of the fatty acid has decreased, while characteristic absorption bands of carboxylate anions ( $\mathrm{COO}^{-} \mathrm{sym}$ metric stretching vibrations, ca. $1400 \mathrm{~cm}^{-1}$ and $\mathrm{COO}^{-}$ antisymmetric stretching vibrations, ca. $1580 \mathrm{~cm}^{-1}$ ) of acid metal salts appeared and their intensity have increased. A highly reliable indication of the absence of both the unreacted acid and hydrated salts in the final product was a zero-absorption in the following infrared regions:

- $3000-3500 \mathrm{~cm}^{-1}$ (O-H stretching vibrations);

- $1700 \mathrm{~cm}^{-1}(C=O$ stretching vibrations $)$;

- $1300 \mathrm{~cm}^{-1}$ (COO-H bending vibrations)

On the other hand, the presence of fatty acid salts was confirmed as distinct bands in the following infrared regions:

$-1580 \mathrm{~cm}^{-1}$ (COO- antisymmetric stretching vibrations),

- $1400 \mathrm{~cm}^{-1}$ (COO- symmetric stretching vibrations) confirmed the presence of fatty acid salts.

The absorption bands at $1380 \mathrm{~cm}^{-1}$ and $1711 \mathrm{~cm}^{-1}$ were selected for the FTIR quantitative determination because of its good correlation between the selected spectral range of the analysis and the change in constituent concentration in standard samples (Figure 3). The Classical Least Squares (CLS) method was used as the calibration model. It provides an equation equivalent to that expressing the Beer-Lambert law that is used to determine the concentrations of constituents with overlapping absorption bands. The CLS method creates a calibration model on the basis of the height or surface area of a peak in the recorded spectrum or measurement points within the spectral range. Quantitative tests provided straight regression lines for the stearate additive in $\mathrm{PE}$ within the concentration range of 0 to $5 \%$ with the correlation coefficient of at least 
Table 3. Analytical monitoring of laboratory scale preparation of iron stearate $\left(\mathrm{FeSt}_{3}\right)-\mathrm{FTIR}$ spectrophotometric testing, comparison with the commercial product (manufacturer: TCI Europe, Belgium)

\begin{tabular}{|c|c|c|c|c|c|c|}
\hline \multirow[b]{2}{*}{ Diagram of reaction } & \multirow[b]{2}{*}{$\begin{array}{l}\text { Correlation with } \\
\text { commercial FeSt } \\
\text { (FTIR - ATR) }(\%)\end{array}$} & \multirow[b]{2}{*}{$\begin{array}{l}\text { Correlation with } \\
\text { comercial FeSt } \\
\text { (FTIR - trans.) (\%) }\end{array}$} & \multirow[b]{2}{*}{$\begin{array}{c}\mathrm{Fe}(\mathrm{II}) \\
\text { content } \\
(\%) \\
(\mathrm{ICP}- \\
\text { OES) }\end{array}$} & \multirow[b]{2}{*}{$\begin{array}{l}\text { Total Fe } \\
\text { content }(\%) \\
\text { (ICP-OES) }\end{array}$} & \multicolumn{2}{|c|}{ Contaminations } \\
\hline & & & & & $\begin{array}{c}\text { Sulphates } \\
\text { content } \\
(\%) \\
\text { (PN-ISO } \\
8214)\end{array}$ & $\begin{array}{c}\text { Chlorides } \\
\text { content } \\
(\%) \\
\text { (PN-ISO 457) }\end{array}$ \\
\hline \multirow{4}{*}{$\begin{array}{l}\mathrm{NaOH}+\mathrm{HSt} \rightarrow \mathrm{NaSt}+\mathrm{H}_{2} \mathrm{O} \\
3 \mathrm{NaSt}+\mathrm{FeCl}_{3} \rightarrow \\
\mathrm{FeSt}_{3}+3 \mathrm{NaCl}\end{array}$} & I-91.46 & - & - & 4.83 & - & 15.9 \\
\hline & II-92.39 & - & - & 6.13 & - & 10.5 \\
\hline & III-93.45 & - & - & 6.46 & - & 9.5 \\
\hline & IV-93.54 & - & - & 7.19 & - & 9.3 \\
\hline $\begin{array}{l}\mathrm{NaOH}+\mathrm{HSt} \rightarrow \mathrm{NaSt}+\mathrm{H}_{2} \mathrm{O} \\
3 \mathrm{NaSt}+\mathrm{FeCl}_{3} \rightarrow \\
\mathrm{FeSt}_{3}+3 \mathrm{NaCl}\end{array}$ & 93.09 & 99.81 & - & - & - & 8.6 \\
\hline $\begin{array}{l}\mathrm{NaOH}+\mathrm{HSt} \rightarrow \mathrm{NaSt}+\mathrm{H}_{2} \mathrm{O} \\
6 \mathrm{NaSt}+\mathrm{Fe}_{2}\left(\mathrm{SO}_{4}\right)_{3} \rightarrow \\
2 \mathrm{FeSt}_{3}+3 \mathrm{Na}_{2} \mathrm{SO}_{4}\end{array}$ & 97.24 & 99.86 & - & - & 0.9 & - \\
\hline $\begin{array}{l}\mathrm{NaOH}+\mathrm{HSt} \rightarrow \mathrm{NaSt}+\mathrm{H}_{2} \mathrm{O} \\
6 \mathrm{NaSt}+\mathrm{Fe}_{2}\left(\mathrm{SO}_{4}\right)_{3} \rightarrow \\
2 \mathrm{FeSt}_{3}+3 \mathrm{Na}_{2} \mathrm{SO}_{4}\end{array}$ & 97.47 & 96.82 & 0.15 & 7.88 & 0.2 & - \\
\hline $\begin{array}{l}\text { Commercial product } \\
\text { (TCl Europe) }\end{array}$ & - & - & 0.08 & 6.45 & 2.8 & 16.9 \\
\hline
\end{tabular}

Abbreviations: $\mathrm{HSt}$ - stearic acid, NaSt - sodium stearate, $\mathrm{FeSt}_{3}$ - iron(III) stearate

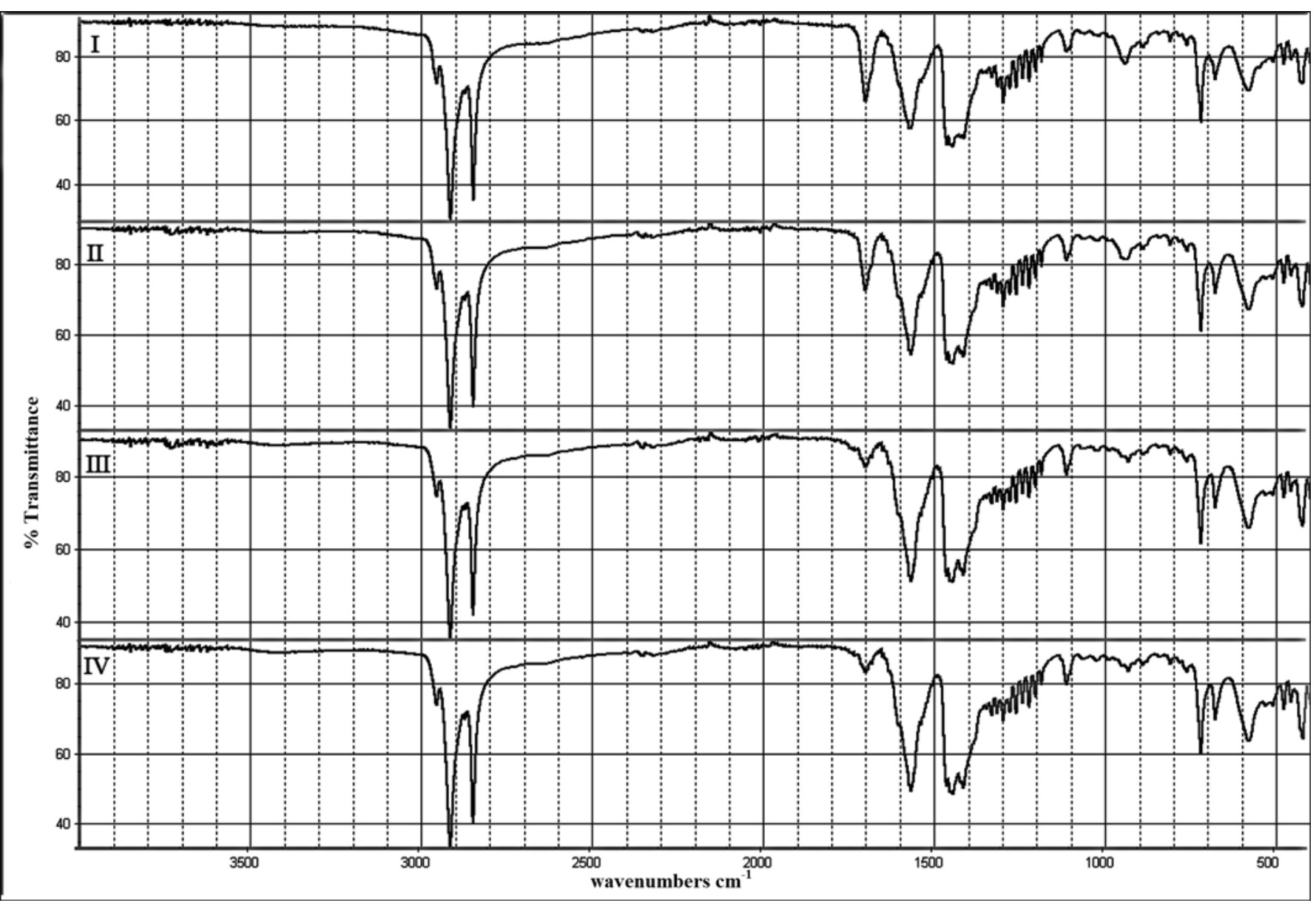

Figure 2. FTIR spectra of iron(III) stearate sample obtained from iron(III) chloride by metathesis reaction after subsequent stages (I - IV) of synthesis

0.999. Films containing larger amounts of prodegradant $(10-20 \%)$ were too thick (differences in the optical path length) and too opaque (poorly transmissive for infrared radiation) to be taken into account in the linear range of calibration. The procedures developed, although not free of limitations resulting from imperfect dispersibility of additives blended with the plastic, seem to be useful in the case of fast determinations for in-process controls.

The thermal characteristics of the synthesis products have been also determined using the DSC method. Heats of transitions and temperatures corresponding to peak maxima were determined. Within the temperature range of 80 to $150^{\circ} \mathrm{C}$ the occurrence of a group of endothermic 


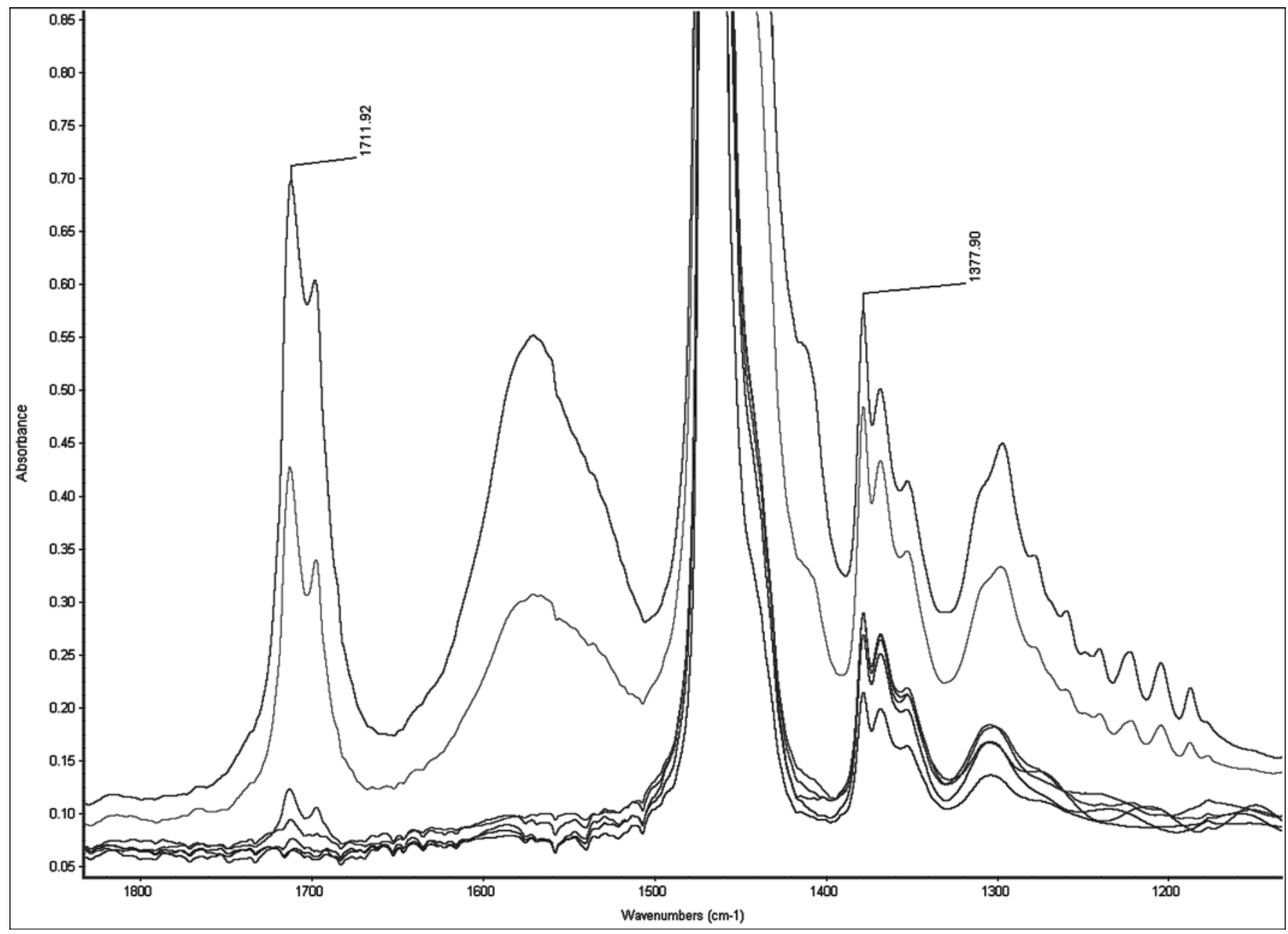

Figure 3. Correlation between the selected spectral range and the change in $0-10 \% \mathrm{FeSt}_{3}$ concentrations in standard samples (Nicolet 380, TQ Analyst EZ Edition)

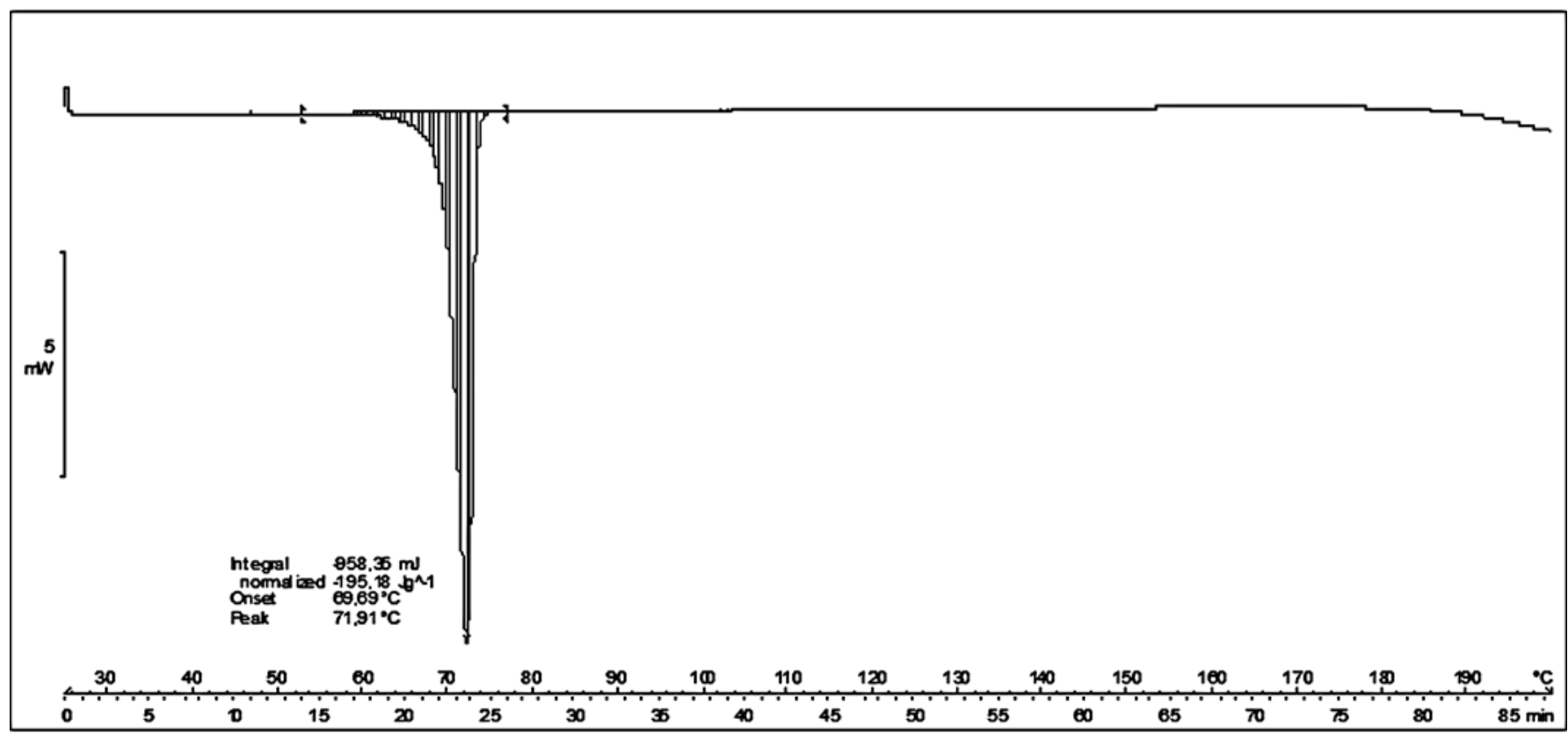

Figure 4. The DSC curve of stearic acid

peaks was established in the acid melting point area of the diagram. Thermal curves of stearic acid (Figure 4) constituted reference points for the analysis of results obtained for the iron stearate samples produced at Fertilizers Research Institute, Department of Inorganic Chemistry "IChN" in Gliwice (Figure 5). The DSC analysis of the subsequent acid-base cycles enabled the control of reaction progress. Gradual diminishing of the band in the 65 to $80^{\circ} \mathrm{C}$ temperature range indicated that the amount of unreacted stearic acid was decreasing. The differences between the results obtained for the different products were an evidence that the individual samples of iron stearates differed slightly in the structure and the physical properties, which resulted from the strength of ionic bonds between iron ions and organic chains, and/or from various $\mathrm{Fe}^{2+} / \mathrm{Fe}^{3+}$ ratio in the samples ${ }^{\mathbf{1 0}}$. 


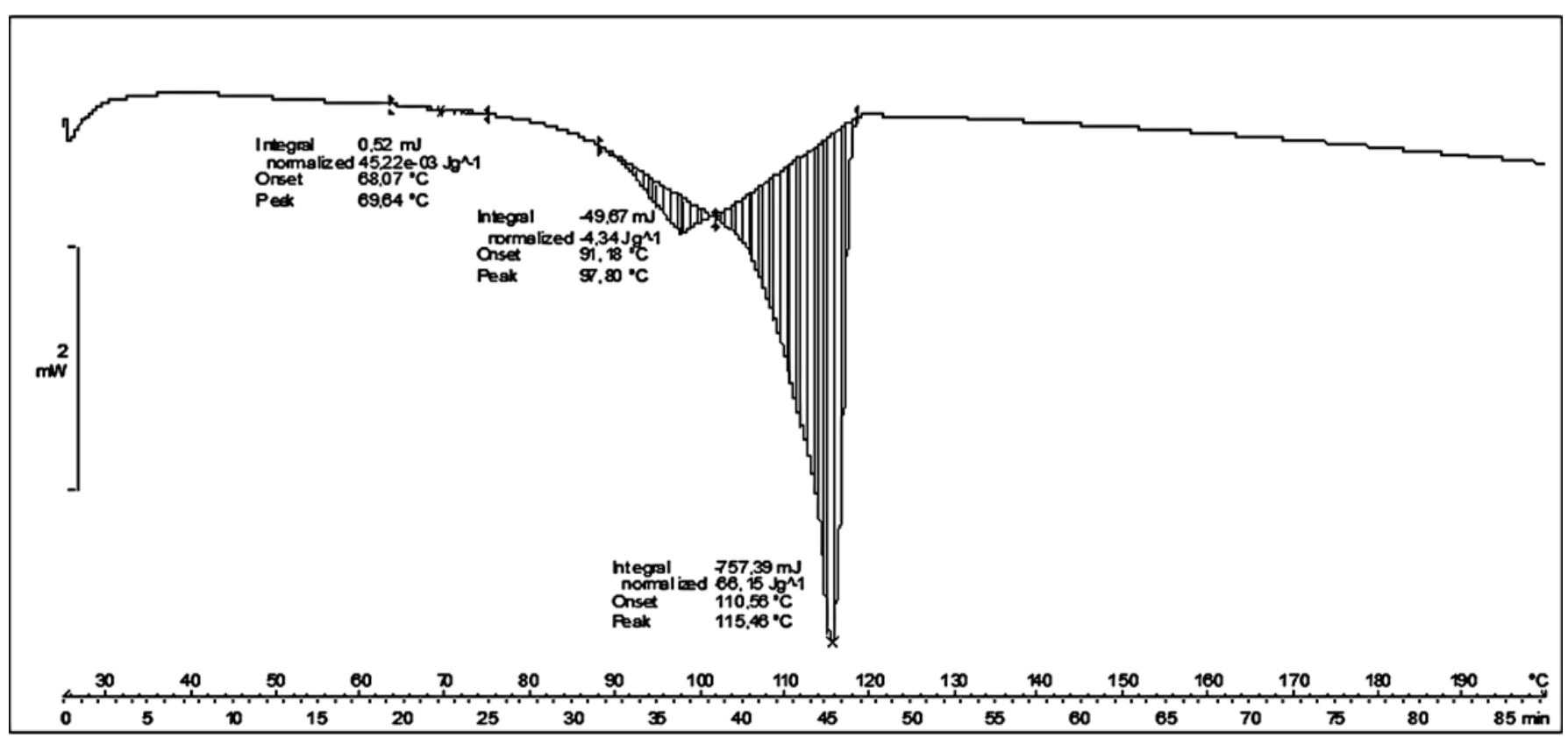

Figure 5. The DSC curve of iron(III) stearate

Microscopy and laser diffraction particle size analysis were applied to determine the size of the precipitated product grains. It is accepted that the modal size (diameter) of an optimum grain of filler should be 10 microns, and that $100 \%$ of the grains should be not larger than 40 microns. The data analysis indicates that the grain size is appropriate for the application and that there is no need to apply the additional comminution or grain forming processes. Microscopic examination confirmed the presence in the product of contamination originating from the unwashed remainder of the second salt formed in the process. The tests performed showed that the product does not have to be highly pure, however it should not contain unreacted sodium stearate or stearic acid.

An application sample of the product obtained by the double decomposition method (Method No 3) from iron(III) sulphate as the iron carrier has successfully passed application tests in polyethylene packaging film (Table 4). As the criterion of the changes in the course of ageing processes, the parameter that changed most rapidly was taken into consideration. In the case of LDPE it was the relative tensile elongation at break. Percentage change in the relative elongation after the defined ageing time was adopted as the criterion for assessing the stabilisation processes (Figure 6). After 1 month of atmospheric ageing (under low sunlight conditions) the onset of the degradation processes was observed. Strength testing results after 6 months of exposure under the conditions of the Polish climate (low sunlight during September - December 2009 period) confirmed the occurrence of the degradation processes.
Film durability (usability) is described by the time necessary for the relative elongation to change by $50 \%$. According to ASTM D 3826 standard (Standard Practice for Determining Degradation End Point in Degradable Polyethylene and Polypropylene Using a Tensile Test) plastic is considered to have reached the so-called brittle point, when it is assumed to have become assimilable by bacteria, when the relative elongation at break is equal to $5 \%$ (or less) of the initial value of an unaged specimen. Research carried out elsewhere has led also to make an assumption that the plastic becomes assimilable by microorganisms when its molecular weight falls below 10.000 $\mathrm{Da}$. The results of ageing tests (under natural conditions) enabled the estimation of the time after which the film underwent degradation to such degree that it became biodegradable (consumable by microorganisms present in soil and water), Table 5 .

It may be assumed that the complete degradation cycle lasts from about 6 months to 1 year.

Table 5. Estimated degradation time of tested films

\begin{tabular}{|l|c|}
\hline $\begin{array}{c}\text { Composition of } \\
\text { film }\end{array}$ & $\begin{array}{c}\text { Estimated time of weathering necessary for } \\
\text { degradation }\end{array}$ \\
\hline $\mathrm{PE}+0.5 \% \mathrm{FeSt}_{3}$ & 11.3 months \\
\hline $\mathrm{PE}+1 \% \mathrm{FeSt}_{3}$ & 8.4 months \\
\hline $\mathrm{PE} / \mathrm{MD} 30 / \mathrm{FeSt}_{3}$ & 6.9 months \\
\hline
\end{tabular}

\section{CONCLUSION}

Disposable packaging made of synthetic plastics is manufactured in growing quantities. The reason is the low cost as compared to the cost of the alternative solutions. Disposal of plastic packaging by biodegradation, includ-

Table 4. Results of application tests carried out at Institute for Engineering of Polymer Materials \& Dyes in Toruń, Department of Paints \& Plastics in Gliwice

\begin{tabular}{|c|c|c|c|c|c|c|c|c|}
\hline \multirow[t]{2}{*}{ Composition of film } & \multirow{2}{*}{$\begin{array}{l}\text { Thickness } \\
{[\mathrm{mm}]}\end{array}$} & \multirow{2}{*}{$\frac{0}{\text { Tensile strength [MPa] }}$} & \multicolumn{2}{|c|}{1 month w.c. } & \multicolumn{2}{|c|}{3 months w.c. } & \multicolumn{2}{|c|}{6 months w.c. } \\
\hline & & & [MPa] & $\varepsilon[\%]$ & [MPa] & $\varepsilon[\%]$ & [MPa] & $\varepsilon[\%]$ \\
\hline $\mathrm{PE}+0.5 \% \mathrm{FeSt}_{3}$ & 0.033 & 33.2 & 31.8 & 96.2 & 20.1 & 75 & 15.7 & 50.7 \\
\hline $\mathrm{PE}+1 \% \mathrm{FeSt}_{3}$ & 0.02 & 45.1 & 26.3 & 79.6 & 19 & 60.2 & 14.3 & 33 \\
\hline $\mathrm{PE} / \mathrm{MD} 30 / \mathrm{FeSt}_{3}$ & 0.301 & 17.1 & 15.4 & 64.2 & 14.9 & 46.8 & 12.2 & 20.5 \\
\hline
\end{tabular}




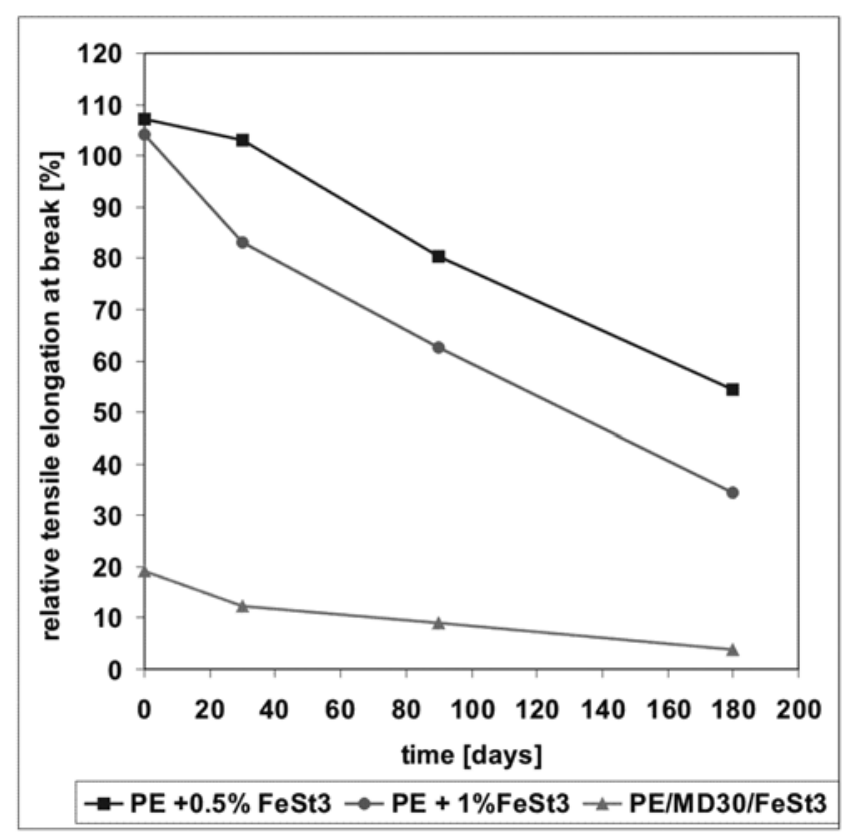

Figure 6. Relative elongation change after defined time of ageing

ing oxo-biodegradation, is a solution for the future. The demand for an additive inducing oxo-biodegradation of polyolefins is growing. In Poland it will certainly rise as the economy is developing and the living standards are improving. The study performed is an element of developing an offer of innovative product technologies (oxoand thermo-biodegradation additives and concentrates thereof for plastics) for the Polish chemical companies looking for new products and technologies with the growing market potential. The iron(III) carboxylate may be applied as the sole prodegradant for polyolefinic plastics or, due to the mechanism of activity by oxo-biodegradation, may form one of the components of a degradation preparation of a broader activity spectrum.

The tests performed showed that the best effects, in terms of process efficiency and application properties, were achieved when iron(III) stearate was obtained by the double decomposition of iron(III) chloride or sulphate. The FTIR spectra and DSC curves have not indicated the presence of the unreacted stearic acid in the products. The obtained compound of transition metal, iron(III), proved to be an effective prodegradant of oxo-degradation processes, which was confirmed by application tests carried out on LDPE film.

The study has been conducted as part of statutory activities of the Institute of Inorganic Chemistry in Gliwice and of the Institute for Engineering of Polymer Materials and Dyes, Gliwice Department.

\section{LITERATURE CITED}

1. Florjańczyk, Z. (2009). Synhetic and natural polymers in modern polymer materials. Polimery 54(10), 691 - 705.

2. Gierucki, Ł. (2008, September). Film package - it's the end? D2W - ecological package of the future, from http:// www.lumex.pl/pl/firma/artykuly/276.html.

3. Wasiak, W. (2009, September). Market package in Poland 2009, from http://www.plastech.pl/wiadomosci/artykul_2972_1/ Rynek-opakowan-w-Polsce-w-2009-r.

4. Gibas, E., Rymarz, G., Zawadiak, J. \& Marek, A. (2009). Modification of polymers. Condition and perspectives in $2009 r$.
Wrocław 20-23 September 2009. Annexe Publishers Wrocław University of Technology, $175-178$.

5. Gibas, E. \& Rymarz, G. (2008). Oxy-biodegradable thermoplastic polymers in production of eco-friendly plastic. Chemik 61(11), 627 - 631.

6. Kumar, P. et al. (2009). Nanoscale particles for polymer degradation and stabilization - Trends and future perspectives. Progress in Polymer Science 34(6), 479 / 515. DOI:10.1016/ j.progpolymsci.2009.01.002.

7. Rydarowski, H. \& Czaplicka, K. (2009, June). Screenplays selection of technological progress of polymers materials. from http://www.science24.com/paper/14851.

8. Kuciel, S., Liber-Kneć, A. \& Zajchowski, S. (2009). Biocomposites based on thermoplastic starch or polylactide/ starch blends as the matrices filled with natural fi bers. Polimery 54(10), 747 - 753.

9. Gibas, E. \& Rymarz, G. (2009). Investigation on the influence of prodegradant kind of polyethylene (LDPE) oxodegradation. Chemik 62(10), 379 - 381.

10. Herng-Dar Hwu, T. et al. (1995). U.S. Patent No. 5,434,277. Washington, D.C.: U.S. Patent and Trademark Office.

11. Biron, M.(2009, July). Industralisation of Suistainable Solution: Modyfication and Blending of Bioplastic, from http:/ /www.specialchem4polymers.com.

12. Stadler, U. (2001). Impact of Stabilization Additiveson the Controlled Degradation of Polypropylene, Polyolefins. Revelling in Reference: Reference and Information Services Section Symphosium, 2001; 25-28.02.2001 Houston, TX The International Conference on Polyolefins.

13. Roy, P. K., Surekha, P., Rajagopal, C., Chatterjee, S. N. \& Choudhary, V. (2006). Effect of cobalt carboxylates on the photo-oxidative degradation of low-density polyethylene. Part-I. Polymer Degradation and Stability 90(9) 1980 - 1988. DOI:10.1016/j.polymdegradstab.2006.02.007.

14. Roy, P.K., Surekha, P., Raman, R. \& Rajagopal, C.(2009). Investigating the role of metal oxidation state on the degradation behavior of LDPE. Polymer Degradation and Stability 94(7), 1033 - 1039. DOI:10.1016/j.polymdegradstab.2009.04.025.

15. Olson, H.M. (1963). U.S. Patent No. 3,078,288. Washington, D.C.: U.S. Patent and Trademark Office.

16. Roy, P.K., Surekha, P., Rajagopal, C. \& Choudhary, V. (2007). Comparative Effects of Cobalt Carboxylates on the Thermo-Oxidative Degradation of LDPE Films. Journal of Applied Polymer Science 103(6), 3758 - 3765. DOI: 10.1002/ app.26630.

17. Żakowska, H. ( 2007). Ecological commercial bags. Package no $62(11), 16-21$.

18. Kirk-Othmer (2000). Chemical Technology Encyclopedia. (4th ed.) Wiley - VCH, vol. 8, $217-222$.

19. Sanderson, R.D., Pasch H. \& Meisel I.(2002). Polymer Characterization and Materials Science. Wiley - VCH, 2002.

20. Eyenga, I.I, Focke, W.W., Prinsloo, L.C. \& A. T. Tolmay, A T. (2002). Photo degradation: A Solution for the Shopping Bag Visual Pollution" Problem?" Macromol. Symp. 178, 139 - 152 DOI:10.1002/1521-3900(200202)178:1<139::AIDMASY139>3.0.CO;2-I.

21. Clendinning, R.A., Potts, J. E. \& Cornell, S. W. (1975). U.S. Patent No. 3921 333. Washington, D.C.: U.S. Patent and Trademark Office. 